\title{
Prognostic Significance of Intrathecal Oligoclonal Immunoglobulin G in Multiple Sclerosis
}

\author{
Sanja Grgić, ${ }^{1,2}$ Aleksandra Dominović Kovačević, ${ }^{1,2}$ Vlado Đajić, ${ }^{1,2}$ \\ Zoran Vukojević,,2 Daliborka Tadić, ${ }^{1,2}$ Duško Račić, ${ }^{1,2}$ Zoran Vujković,
}

\section{Abstract}

Introduction/Aim: Detection of intrathecal oligoclonal bands of immunoglobulin G (OB IgG), in addition to diagnostic, has a predictive significance in multiple sclerosis (MS). The aim of the study was to determine the prognostic significance of $\mathrm{OB}$ $\mathrm{IgG}$ and to correlate the presence of $\mathrm{OB} \operatorname{IgG}$ with the progression of disability in MS patients.

Methods: A retrospective-prospective cohort study included 177 MS patients examined at the Centre for MS, Clinic of Neurology, University Clinical Centre of the Republic of Srpska. In all patients, demographic data, clinical parameters, Expanded Disability Status Scale (EDSS) score, isoelectric focusing (IEF) of cerebrospinal fluid (CSF), cyto-biochemical analysis of CSF, evoked potentials (EP) and magnetic resonance (MR) of the head were analysed. MS patients were divided in two groups: with and without intrathecal synthesis of oligoclonal IgG. According to the EDSS determined in both groups, the relation between the degree of functional disability and the presence of OB in the CSF and also with characteristics of the cyto-biochemical profile were analysed. Methods of descriptive and analytical statistics, analysis of variance, chi-square test, Bonferroni's post hoc test, correlation and regression analysis were used in the analysis of the results.

Results: In the examined cohort of MS patients, the sensitivity of IEF was $96.6 \%$. There was a statistically significant association between the detectability of intrathecally synthesised IgG and EDSS score $(p=0.004)$ so that individuals who do not have intrathecally synthesised IgG had lower EDSS scores. MS patients with a CSF protein concentration $>0.40 \mathrm{~g} / \mathrm{L}$ were 2.45 times more likely to enter secondary progression and 2.51 times more likely to achieve EDSS 4.0.

Conclusion: IEF is a very sensitive diagnostic and prognostic method for MS patients, which indicates a more benign course of MS in patients without oligoclonal bands in the CSF.

Key words: Oligoclonal bands; Multiple sclerosis; Prognosis.

\section{Introduction}

By analysing the quantitative and qualitative disorders of cerebrospinal fluid (CSF) IgG in patients with multiple sclerosis (MS), it is possible to obtain very significant diagnostic and prognostic data. ${ }^{1}$ Recommended criteria for CSF analysis in-
(1) Clinic of Neurology, University Clinical Centre of the Republic of Srpska, Banja Luka, the Republic of Srpska, Bosnia and Herzegovina.

(2) Faculty of Medicine, University of Banja Luka, Banja Luka, the Republic of Srpska, Bosnia and Herzegovina.

Correspondence: SANJA GRGIĆ

E: grgic@teol.net

M: +38165663 997

\section{ARTICLE INFO}

Received: 17 July 2020

Revision received: 18 August 2020 Accepted: 19 August 2020

Copyright $\odot 2020$ Grgić et al. This is an open access article distributed under the Creative Commons Attribution License (CC BY), which permits unrestricted use, distribution, and reproduction in any medium, provided the original work is properly cited. This article should be cited as follows: Grgić S, Dominović Kovačević A, Đajić V, Vukojević Z, Tadić D, Račić D, Vujković Z. Prognostic significance of intrathecal oligoclonal immunoglobulin G in multiple sclerosis. Scr Med 2020;51(3):147-51. 
MS experts consider magnetic resonance (MR) alone to be insufficient for the diagnosis and prognosis of MS. ${ }^{3}$ CSF testing helps predict conversion to MS in patients with negative MR or with lesions that do not meet diagnostic criteria. ${ }^{4}$ In patients with negative MR, the presence of OB increases the risk of MS by 4-23 \% . ${ }^{5}$ Along with $\mathrm{OB}$, numerous markers in the CSF are specific to the disease process, such as inflammation and immune dysfunction. Some of these markers have predictive significance in the conversion of the Clinically Isolated Syndrome (CIS) to MS. ${ }^{6,7}$ Increased conversion was observed in the presence of IgG antibodies to neurotropic viruses, rubella, varicella-zoster, which are responsible for nonspecific polyclonal activation of B cells within the central nervous system. ${ }^{8}$ CSF markers of an axonal lesion may be more specific than MR to predict CIS conversion to MS.9, 10

Frederikson et al pointed out that, in addition to diagnostic significance, the detection of $\mathrm{OB}$ of immunoglobulin $\mathrm{G}$ has the highest predictive sensitivity of conversion of CIS to MS and that there is a correlation between $\mathrm{OB}$ and disability progression. ${ }^{11}$ In some patients (5-10 \%) with clinically confirmed MS, OBs in the CSF are not detected regardless of the sensitivity of the method. Among the patients without OB in the CSF, the majority are those with a benign course of the disease. ${ }^{12,13}$

The aim of the study is to determine the prognostic significance of OB IgG and to correlate the presence of OB IgG with the progression of disability in MS patients.

\section{Methods}

The study is a cohort, partly retrospective, and partly prospective. It included all MS patients whose CSF was analysed by the IEF method with immunofixation at the Neuroimmunological Laboratory of the Clinic of Neurology, University Clinical Centre of the Republic of Srpska for three and a half years. All patients signed informed consent before entering the study. The study was approved by the Ethics Committee of University Clinical Centre of the Republic of Srpska, Banja Luka, Republic of Srpska, Bosnia and Herzegovina.
All CSF and serum samples were analysed by the standardised IEF method. 2, 3, 5 The study included 177 MS patients, of which 55 were men and 122 women (ratio 1: 2.2 in favour of women). The mean age \pm standard deviation (SD) of MS patients at the time of the study was $38.8 \pm 10.7$ years and the mean age of patients at the disease onset was $34.4 \pm 8.4$ years. The average duration of the disease was $4.4 \pm 6.0$ years. According to the course of the disease, the most common is the relapsing-remitting (RR) form of MS (79.7 \%), followed by the secondary-progressive (SP) (13.6\%) and primary-progressive (PP) (6.8\%) form of MS. The mean EDSS score in patients with MS was 2.7 \pm 1.7. Progression index (PI = EDSS/duration of the disease ${ }^{14}$ was calculated for all MS patients and a mean value was $2.70 \pm 4.78$. The disease was more active in the first compared to the second year of the disease, because in the first year of the disease the average number of relapses was $1.5 \pm 0.6$ and in the second year $1.3 \pm 0.7$.

All material was analysed in the mentioned period and the IEF was interpreted with the data on the temporary diagnostic assumption. All MS patients were diagnosed according to McDonald criteria (2005 revision). ${ }^{10,14}$ The degree of functional disability was determined by using the EDSS score ${ }^{15}$ at least 30 days after relapse. Beside EDSS, for all patients, the PI was calculated.

All MS patients were examined for demographic and clinical parameters and the following diagnostic procedures were performed: cyto-biochemical analysis of CSF, IEF of CSF and serum, evoked potentials battery - visual evoked potentials (VEP), auditory evoked potentials (AEP) and somatosensory evoked potentials (SSEP) by stimulating median nerve and MR of the head.

Based on the IEF findings, the group of MS patients was divided into two groups:

(1) with intrathecal synthesis of oligoclonal IgG and

(2) without intrathecal synthesis of oligoclonal IgG.

Qualitative testing of IgG in CSF and serum was performed by the IEF method of CSF and serum on agarose with protein transfer to the nitrocellulose membrane, immunofixation and staining with immunoperoxidase. According to the EDSS determined in both groups of MS patients, the relation between the degree of functional disability 
and the presence of OB in the CSF was analysed. The association of the cyto-biochemical profile with EDSS and the predictive significance of such association for MS were investigated.

Descriptive and analytical statistical methods were used in the analysis of the results. Analysis of variance (ANOVA) was used to estimate differences among continuous variables, and the $\chi^{2}$ test was used for categorical variables. Bonferroni's post hoc test was used for multiple intergroup differences. Correlation analyses included the calculation of Spearman's correlation rank coefficient for nonparametric data. Statistical significance was determined at the level of 0.05 .

\section{Results}

IEF of CSF and serum was done in all patients, and out of 177 MS patients, intrathecal synthesis was detected in 171 patients (96.6\%), which indicates a very high sensitivity of the method. Comparing the group of MS patients with OB and those without intrathecal synthesis, it was observed that all patients with regular IEF findings had the RR form of the disease, the disease lasted up to a year, average EDSS $=1.0$ and the average number of relapses in the first year was one. From the above mentioned clinical parameters of the MS patients with OB, it can be seen that in the group without local synthesis there are no patients in SP and PP form of MS, that the disease lasted shorter, the mean EDSS score was lower and that the disease activity was lower in the first year. In this study, the presence of a statistically significant difference in the positivity of IEF

Table 1: Significance of the difference between IEF and EDSS positivity and progression index in MS patients

\begin{tabular}{|c|c|c|c|c|}
\hline & & $\mathbf{N}$ & Mean & $\begin{array}{l}\text { Standard } \\
\text { deviation }\end{array}$ \\
\hline \multirow{3}{*}{ EDSS } & Negative IEF & 6 & 0.7500 & 0.61237 \\
\hline & Positive IEF & 171 & 2.8099 & 1.71939 \\
\hline & Total & 177 & 2.7401 & 1.73376 \\
\hline \multicolumn{5}{|c|}{$p=0.004$} \\
\hline \multirow{3}{*}{$\begin{array}{l}\text { Index of } \\
\text { progression }\end{array}$} & Negative IEF & 6 & 4.8333 & 6.21021 \\
\hline & Positive IEF & 171 & 2.6301 & 4.73783 \\
\hline & Total & 177 & 2.7047 & 4.78929 \\
\hline \multicolumn{5}{|c|}{$p=0.269$} \\
\hline \multicolumn{5}{|c|}{$\begin{array}{l}\text { IEF - isoelectric focusing of the cerebrospinal fluid } \\
\text { EDSS - Expanded Disability Status Scale }\end{array}$} \\
\hline
\end{tabular}

(intrathecally synthesised IgG) according to clinical parameters as variables was examined. The results indicated that there was no statistically significant association between IEF positivity and gender, age, level of education, age at onset, and duration of MS disease. There was a statistically significant association between the detectability of intrathecally IgG and EDSS score (p = 0.004 ) so that individuals who do not have intrathecally synthesised IgG have lower EDSS scores

Table 2: MS Outcome: secondary progression as a function of CSF variables

\begin{tabular}{lrcr}
\hline Variable & HR & $\mathbf{9 5 \%}$ Cl & p \\
\hline Proteins $(>0.40)$ & 2.45 & $1.01-5.99$ & 0.049 \\
\hline Cell number $(>5)$ & 1.45 & $0.49-4.32$ & 0.504 \\
\hline MS - multiple sclerosis & & & \\
CSF - cerebrospinal fluid & & & \\
HR - hazard ratio & & & \\
Cl - confidence interval & & &
\end{tabular}

(Table 1). There was no statistically significant association between the positivity of the IEF and the progression index, protein concentration and cell number in the CSF of MS patients.

Cyto-biochemical analysis of CSF in MS patients found a mean protein value of $0.39 \pm 0.1 \mathrm{~g} / \mathrm{L}$ (range 0.1-1.0 g/L). The mean number of cells in the CSF of MS patients was $4.8 \pm 6.8$.

Table 3: MS Outcome: EDSS 4.0 scores as a function of CSF variables

\begin{tabular}{lrrr}
\hline Variable & HR & $\mathbf{9 5 \%}$ Cl & $\mathbf{p}$ \\
\hline Proteins $(>0.40)$ & 2.51 & $1.23-5.12$ & 0.049 \\
\hline Cell number $(>5)$ & 1.24 & $0.54-2-85$ & 0.504 \\
\hline$M S-$ multiple sclerosis \\
EDSS - Expanded Disability Status Scale \\
CSF - cerebrospinal fluid \\
HR - hazard ratio \\
Cl - confidence interval
\end{tabular}

A statistically significant predictor of progression in this series of patients was the protein concentration $>0.40 \mathrm{~g} / \mathrm{L}$. MS patients with a CSF protein concentration $>0.40 \mathrm{~g} / \mathrm{L}$ were 2.45 times more likely to enter secondary progression (Table 2). A statistically significant predictor of achieving EDSS 4.0 in this series of patients was a protein concentration $>0.40 \mathrm{~g} / \mathrm{L}$. This means that MS patients with a CSF protein concentration $>0.40$ $\mathrm{g} / \mathrm{L}$ are 2.51 times more likely to achieve EDSS 4.0 (Table 3). In this series of MS patients, no variable showed a statistically significant predictive value for achieving EDSS 6.0. IEF was not included in predictive models because in this series of MS patients there were only six IEF findings without intrathecal IgG synthesis, but a statistically sig- 
nificant association between IEF and EDSS positivity indicates a more benign disease course in patients without local synthesis.

\section{Discussion}

Numerous studies have shown that IEF is the most sensitive method of detecting intrathecal IgG synthesis, which gives it a great diagnostic value. ${ }^{16-19}$ For the method to have full clinical potential for OB IgG analysis in CSF, standardisation of laboratory methods and diagnostic criteria is necessary. ${ }^{20,21}$ Results of the present study showed high sensitivity of the IEF method (96.6\%) in the examined group of MS patients in this laboratory. Recent studies have shown that the detection of OB in the CSF has a predictive significance for the course of the disease and the progression of disability expressed by EDSS score.22-25 This study indicated that there was a statistically significant association between the detectability of intrathecally synthesised IgG and EDSS score ( $p=0.004)$ so that individuals who do not have intrathecally synthesised IgG have lower EDSS scores.

When the groups of examined MS patients with and without OB were compared, it was noticed that all patients without OB in the CSF had the RR form of the disease, that the disease lasted up to a year, the average EDSS was 1.0, and the average number of relapses in the first year was one. Therefore, in the group of MS patients without local synthesis there were no patients with the progressive forms (SP and PP) of MS, the disease lasted shorter, the average EDSS score was lower and the disease activity was lower in the first year. Significant prospective studies with similar results have indicated that patients with negative OB have a better prognosis in terms of neurological disability, due to a more benign course of the disease. ${ }^{26-30}$ In 2013, Mero et al pointed out that MS patients without OB were immunogenetically different from typical MS patients with OB. ${ }^{31} \mathrm{Im}$ rell and co-authors showed that patients with $\mathrm{OB}$ had a more aggressive course of the disease compared to those without OB. This imposes the importance of IEF in a predictive sense, but also in an attempt to understand the pathogenic mechanisms in MS patients with and without OB. ${ }^{32}$

In 2012, Lourenco et al conducted a large retrospective study on a sample of 6,935 MS patients. ${ }^{33}$ The results of the study presented in the paper here follow the results of the mentioned study and both studies have highlighted a significant difference in the positivity of the IEF according to the degree of the functional disability expressed by the EDSS score, without a significant difference regarding the progression index. This showed that MS patients without local synthesis had a more benign course and a lower EDSS score. Along with $\mathrm{OB}$, numerous biological markers in the CSF are specific to the disease process, such as high protein levels as a sign of inflammation and immunodysfunction. ${ }^{34,35}$ Studies indicate that proteins at high concentrations in the CSF have a predictive significance for the progressive course of MS. ${ }^{36-38}$ In the study presented here, a statistically significant predictor of secondary progression and reaching EDSS 4.0 in the examined MS patients was a protein concentration of more than $0.40 \mathrm{~g} / \mathrm{L}$. MS patients who have a CSF protein concentration of more than $0.40 \mathrm{~g} / \mathrm{L}$ are 2.45 times more likely to enter secondary progression and 2.51 times more likely to reach EDSS4.0.

\section{Conclusion}

Numerous studies in this area have indicated that the presence of OB in the CSF of MS patients in addition to diagnostic has an exceptional predictive significance. The results of the present study indicate that MS patients with intrathecal IgG synthesis have a higher degree of functional disability expressed by the EDSS score. Also, an elevated CSF protein concentration was confirmed as a predictor of MS progression. Everything mentioned indicates that the study of numerous markers in the CSF enables a better understanding of the aetiology, pathophysiology, course and prognosis of MS, and allows us to make timely and adequate therapy choices for MS patients.

\section{Acknowledgements}

None.

\section{Conflict of interest}

None. 


\section{References}

1. Awad A, Hemmer B, Hartung HP, Kieseier B, Bennett JL, Stuve 0. Analyses of cerebrospinal fluid in the diagnosis and monitoring of multiple sclerosis. J Neurol. 2010;219:1-7.

2. Grgić S. [Importance of intrathecal oligoclonal immunoglobuline $\mathrm{G}$ in diagnosis and prognosis of multiple sclerosis] [dissertation]. Banja Luka: Faculty of Medicine, University of Banja Luka; 2013. Serbian.

3. Drulović J. [Analysis of oligoclonal immunoglobuline G in differential dijagnosis of neurological diseases] [dissertation]. Faculty of Medicine, University of Belgrade; 1994. Serbian.

4. Rolas JI, Patricco TS, Cristiana E. Oligoclonal bands in multiple sclerosis patients: worse prognosis. Neurol Res 2012;34(9):889-92.

5. Drulović J, Stojisavljević N, Dujmović. Findings of cerebrospinal fluid in the diagnosis of multiple scleorosis. Srp Arh Celok Lek 1995;123:7-8.

6. Dell Avvento S, Sotgio MA, Mance S, Sotgiu G, Sotgiu S. Epidemiology of multiple sclerosis in the pediatric population of Sardinia, Italy. Eur J Pediatr 2016;175(1):1921.

7. Waldman A, Ghezzi A, Bar-Or A, Mikaeloff Y, Tardieu M, Banwell B. Multiple sclerosis in children: an update on clinical diagnosis therapeutic strategies, and research. Lancet Neurol 2014;13(9):936-48.

8. Ghasemi N, Razavi S, Nikzad E. Multiple Sclerosis: pathogenesis, symptoms, diagnosis and cell-based therapy. Cell J 2017;19(1): 1-10.

9. Holloman JP, Ho CC, Hukki A, Huntley JL, Gallicano GI. The development of hematopoietic and mesenchymal stem cell transplantation as an effective treatment for multiple sclerosis. Am J Stem Cells 2013;2(2):95-107.

10. Gelfand JM. Multiple sclerosis: diagnosis, differential diagnosis, and clinical presentation. Handb Clin Neurol 2014;122:269-90.

11. Fredrikson S. Clinical usefulness of cerebrospinal fluid evaluation. Intern Mult Scler J 2010;17:24-27.

12. Dutta R, Trapp BD. Relapsing and progressive forms of multiple sclerosis - insights from pathology. Curr Opin Neurol 2014;27(3):271-8.

13. Miller DH, Chard DT,Cicconelli O.Clinically isolated syndromes. Lancet Neurol 2012;11:157-69.

14. Dujmovic BI, Drulović J, Pekmezovic T. [Prirodni tok i prognoza multiple skleroze]. In: Drulović J, editor. Multiple sclerosis. Belgrade: Faculty of Medicine, Univerzitety of Belgrade; 2013. p. 32-46. Serbian.

15. Lublin FD, Reingold SC, Cohen JA, Cutter GR, Sørensen PS, Thompson AJ, et al. Defining the clinical course of multiple sclerosis: the 2013 revisions. Neurology 2014; 83(3):278-86.

16. Stangel M, Fredrikson S, Meinl E, Petzold A, Stüve O, Tumani $\mathrm{H}$. The utility of cerebrospinal fluid analysis in patients with multiple sclerosis. Nat Rev Neurol 2013 May;9(5):267-76.

17. Katsavos S, Anagnostouli M. Biomarkers in multiple sclerosis: an up-to-date overview. Mult Scler Int 2013; 2013:340508. doi: 10.1155/2013/340508.

18. Immunodetection of oligoclonal bands in serum and CSF of Multiple Sclerosis patients. Ann Neurosci 2015;22(1):54. 10.5214/ans.0972.7531.220213

19. Sun X, Bakhti M, Fitzner D. Quantified CSF antibody reactivity against myelin in multiple sclerosis. Ann Clin Transl Neurol 2015;2(12):1116-23.

20. Engelborghs S. Consensus guidelines for lumbar puncture in patients with neurological diseases. Alzheimers Dement (Amst) 2017; 8:111-26.

21. Dominques RB, Peres Fernandes GB, de Moura Leite
FBV, Tilbery CP, Thomaz RB, Silva GS, et al. The cerebrospinal fluid in multiple sclerosis: far beyond the bands. Einstéin (Sao Paulo) 2017 Jan-Mar;15(1):100-4.

22. Frau J, Villar LM, Sardu C, Secci MA, Schirru L, Ferraro $D$, et al. Intrathecal oligoclonal bands synthesis in multiple sclerosis: is it always a prognostic factor? J Neurol 2018;265(2):424-30.

23. Kuhle J, Disanto G, Dobson R, Adiutori R, Bianchi I, Topping J, et al. Conversion from clinically isolated syndrome to multiple sclerosis: a large multicenter study. MSJ 2015;21(8):1013-24.

24. Ruet A, Arrambide G, Brochet B, Auger C, Simon E, Rovira A, et al. Early predictors of multiple sclerosis after a typical clinically isolated syndrome. Mult Scler 2014;20:1721-26.

25. Grgic S, Dominovic-Kovacevic A, Vukojevic Z. The significance of oligoclonal intrathecal immunoglobulin $G$ in the diagnosis of multiple sclerosis. Curr Top Neurol Psychiatr Relat Discip 2014;22(3-4):11-9.

26. Avasarala JP, Cross AH, Trotter JL. Oligoclonal band number as a marker for prognosis in multiple sclerosis. Arch Neurol 2001;18:2044-6.

27. Schneger R, Souza MD, Schindler C, Grize L, Dellas S, Radne EW. Prediction of long-term disability in multiple sclerosis. Mult Scler 2012;18(1):31-8.

28. Thompson AJ, Banwell BL, Barkhof F, Carroll WM, Coetzee T, Comi G et al. Diagnosis of multiple sclerosis: 2017 revision of the McDonald criteria. Lancet Neurol 2018;17(2):162-73.

29. Gaetani L, Prosperini L, Mancini A. 2017 revisions of McDonald criteria shorten the time to diagnosis of multiple sclerosis in clinically isolated syndromes. J Neurol 2018;265(11):2684-7.

30. Aktas O, Wattjes MP, Sangel M, Hartung H-P. [Diagnosis of multiple sclerosis: revision of the McDonald criteria 2017]. Nervenarzt 2018 Dec; 89(12):1344-54. German.

31. Mero IL, Gustavsen MW, Saether HS, Flam ST, Hansen $\mathrm{PB}$, Sondergaard $\mathrm{HB}$, et al. Oligoclonal band status in Scandinavian multiple sclerosis patients is associated with specific genetic risk alleles. PLos One 2013;8(3):e58352 doi:10.1371/journal.pone.0058352

32. Imrell K, Landtblom AM, Hillert J, Masterman T. Multiple sclerosis with and without CSF bands: clinically indistinguishable but immunogenetically distinct. Neurology 2006;67(6):1062-4

33. Lourenco P, Shiran A, Saeedi J, Oger J, Schreiber A Tremlett H. Oligoclonal bands and cerebrospinal fluid markers in multiple sclerosis: associations with disease course and progression. Mult Scler 2012;1(0):1-8.

34. Ontaneda D, Fox RJ. Progressive multiple sclerosis. Curr Opin Neurol 2015 Jun;28(3):237-43.

35. Brändle SM, Obermeier B, Senel M. Distinct oligoclonal band antibodies in multiple sclerosis recognize ubiquitous self-proteins. Proc Natl Acad Sci U S A 2016 Jul 12;113(28):7864-9.

36. Avsar T, Korkmaz D, Tütüncü M, Demirci NO, Saip S, Kamasak M, et al. Protein biomarkers for multiple sclerosis: semi-quantitative analysis of cerebrospinal fluid candidate protein biomarkers in different forms of multiple sclerosis. Mult Scler 2012 Aug;18(8):1081-91.

37. Deisenhammer F, Zetterberg H, Fitzner B, Zettl UK. The cerebrospinal fluid in multiple sclerosis. Front Immunol 2019 Apr 12;10:726. doi: 10.3389/fimmu.2019.00726.

38. McNicholas N, Hutchinson M, McGuigan C, Chataway J. 2017 McDonald diagnostic criteria: a review of the evidence. Mult Scler Rel Disord 2018 Aug;24:48-54. doi: 10.1016/j.msard.2018.05.011. 